\title{
Healthy Chilean Adolescents with HOMA-IR $\geq 2.6$ Have Increased Cardiometabolic Risk: Association with Genetic, Biological, and Environmental Factors
}

\author{
R. Burrows, ${ }^{1}$ P. Correa-Burrows, ${ }^{1}$ M. Reyes, ${ }^{1}$ E. Blanco, ${ }^{2}$ C. Albala, ${ }^{1}$ and S. Gahagan ${ }^{2}$ \\ ${ }^{1}$ Institute of Nutrition and Food Technology, University of Chile, Avenida El Líbano 5524, Macul, 7840390 Santiago, Chile \\ ${ }^{2}$ Division of Child Development and Community Health, University of California, San Diego, 9500 Gilman Drive, \\ MC 0927, La Jolla, San Diego, CA 92093-0927, USA
}

Correspondence should be addressed to R. Burrows; rburrows@inta.uchile.cl

Received 24 November 2014; Revised 6 January 2015; Accepted 7 January 2015

Academic Editor: Joseph Fomusi Ndisang

Copyright (C) 2015 R. Burrows et al. This is an open access article distributed under the Creative Commons Attribution License, which permits unrestricted use, distribution, and reproduction in any medium, provided the original work is properly cited.

\begin{abstract}
Objective. To determine the optimal cutoff of the homeostasis model assessment-insulin resistance (HOMA-IR) for diagnosis of the metabolic syndrome (MetS) in adolescents and examine whether insulin resistance (IR), determined by this method, was related to genetic, biological, and environmental factors. Methods. In 667 adolescents (16.8 $\pm 0.3 \mathrm{y})$, BMI, waist circumference, glucose, insulin, adiponectin, diet, and physical activity were measured. Fat and fat-free mass were assessed by dual-energy X-ray absorptiometry. Family history of type 2 diabetes (FHDM) was reported. We determined the optimal cutoff of HOMA-IR to diagnose MetS (IDF criteria) using ROC analysis. IR was defined as HOMA-IR values above the cutoff. We tested the influence of genetic, biological, and environmental factors on IR using logistic regression analyses. Results. Of the participants, $16 \%$ were obese and $9.4 \%$ met criteria for MetS. The optimal cutoff for MetS diagnosis was a HOMA-IR value of 2.6. Based on this value, 16.3\% of participants had IR. Adolescents with IR had a significantly higher prevalence of obesity, abdominal obesity, fasting hyperglycemia, and MetS compared to those who were not IR. FHDM, sarcopenia, obesity, and low adiponectin significantly increased the risk of IR. Conclusions. In adolescents, HOMA-IR $\geq 2.6$ was associated with greater cardiometabolic risk.
\end{abstract}

\section{Introduction}

Insulin resistance (IR) is the most common metabolic alteration related to obesity and represents an important link between obesity and other metabolic and cardiovascular complications related to oxidative stress and inflammation [1]. IR is acknowledged to be critical in the development of type 2 diabetes (T2D) and has been associated with obesity, metabolic syndrome (MetS), hypertension, and ischemic cardiovascular disease $[1,2]$. Although impaired beta-cell function is ultimately responsible for T2D, IR precedes betacell dysfunction and, thus, plays a major role in the pathogenesis of this chronic disease [2]. Insulin resistance has become a serious health issue in the pediatric and adolescent age group [3]. In children and adolescents, IR is significantly related to obesity, cardiometabolic risk, and inflammation [3-6]. Family history of type 2 diabetes (FHDM), ethnicity, pre- and postnatal nutritional environment, obesity, puberty, diet, and sedentary lifestyle can all influence insulin sensitivity in the pediatric population [4].

In many developing countries, the nutritional transition and particularly the "westernization" of life-styles have caused a significant rise in obesity and comorbidities associated with IR, including T2D and ischemic cardiovascular disease [7-9]. Chile is a middle income country that underwent a profound shift from under- to overnutrition in less than two decades. Western dietary patterns and inactive lifestyles are widely spread in all age groups, especially among people from middle-low and low to middle socioeconomic status (SES) $[10,11]$. The prevalence of obesity in Chilean children and adolescents more than tripled (5\% to $17 \%$ ), since the early 1990 s $[12,13]$. In a study of obese children and adolescents, $53 \%$ and $30 \%$ had IR and MetS, respectively [14]. According to evidence from another sample of obese Chilean adolescents, 
insulin resistance was associated with higher risk of Mets [15].

Although hyperinsulinemic-euglycemic clamp is the gold standard method for assessment of insulin sensitivity, it is expensive and invasive. Alternative methods based on surrogate markers derived from fasting insulin and glucose, such as the homeostasis model assessment-insulin resistance (HOMA-IR), have been validated and proposed [16, 17]. HOMA-IR values $\geq 2.5$ indicate IR in adults [17], but the corresponding cutoff value for children and adolescents has not been determined [4]. In many studies, IR diagnosis is based on HOMA-IR distribution in a reference population $[15,18]$. MetS in pediatric population has been considered for defining the HOMA-IR cutoff point for IR diagnosis, in several contexts around the world $[19,20]$.

This research aims to determine the optimal cutoff value of HOMA-IR for MetS diagnosis in healthy adolescents, to examine whether IR assessed by using this cutoff value is related to anthropometric, metabolic, and cardiovascular risk profile, and to evaluate the association of IR with genetic, biological, and environmental factors.

\section{Methods and Procedures}

2.1. Study Design and Population. We studied 667 16- to 17year-old adolescents living in urban Santiago, from low to middle SES neighborhoods, who were part of an iron deficiency anemia preventive trial and follow-up study beginning in infancy [21]. The participants were assessed in adolescence to understand biological and psychosocial determinants of adolescent obesity and cardiovascular risk. The study was approved by the institutional review boards of the University of Michigan, Institute of Nutrition and Food Technology (University of Chile), and the University of California San Diego. Participants and their primary caregiver provided informed and written consent, which was obtained according to the norms for Human Experimentation, Code of Ethics of the World Medical Association (Declaration of Helsinki, 1995).

\subsection{Measurements}

2.2.1. Anthropometry and Body Composition. A research physician used standardized procedures to measure the adolescent's height $(\mathrm{cm})$ to the nearest $0.1 \mathrm{~cm}$, using a Holtain stadiometer and weight $(\mathrm{kg})$ to the nearest $0.1 \mathrm{~kg}$ using a Seca scale. Body mass index (BMI) $\left(\mathrm{Kg} / \mathrm{m}^{2}\right)$ was calculated and obesity status was calculated according to WHO references. Measurements were taken twice, with a third measurement, if the difference between the first two exceeded $0.3 \mathrm{Kg}$ for weight and $0.5 \mathrm{~cm}$ for height. Waist circumference was measured with nonelastic flexible tape at the high point of the iliac crest around the abdomen and recorded to $0.1 \mathrm{~cm}$. Measurements were taken twice, with a third measurement, if the difference between the first two exceeded $1.0 \mathrm{cms}$. Dualenergy X-ray absorptiometry (DEXA) was used to measure fat mass (\%) and fat-free mass (\%). Fat-Free Mass Index (FFMI) was estimated according to Wells and Fewtrell [22].
FFMI values were expressed as percentage of BMI; values $\leq$ 25 th percentile in our sample were considered sarcopenia, after adjusting for sex.

2.2.2. Additional Cardiovascular Risk Markers. After 15 minutes at rest and prior to the physical examination, systolic and diastolic blood pressures (SBP and DBP) were measured, three times on the nondominant arm using a standard mercury sphygmomanometer; the average value was used for analyses. Fasting serum total glucose (Gli), cholesterol, triglycerides (TG), high-density lipoprotein (HDL), insulin, adiponectin, and high sensitivity C-reactive protein (hsCRP) levels were performed after a 12-hour overnight fast. Radioimmunoassay (RIA DCP Diagnostic Products Corporation, LA, USA) was used for insulin and adiponectin determinations. High sensitivity C-reactive protein (hs-CRP) was measured with a sensitive latex-based immunoassay (latex-enhanced nephelometry method). Glucose was measured with enzymatic-colorimetric test (QCA S.A. Amposta, Spain) and cholesterol profile (Col-HDL and TG mg/dL) was determined by analytical methodology dry (Vitros, Johnson \& Johnson, Clinical Diagnostics Inc.). Values of hs-CRP $\geq$ $1.1 \mathrm{mg} / \mathrm{L}$ (75th percentile in our sample) were considered lowgrade systemic inflammation and adiponectin $\leq 7.9 \mu \mathrm{g} / \mathrm{mL}$ (25th percentile in our sample) was considered to be low. HOMA-IR was calculated and the optimal cutoff value of HOMA-IR to diagnose MetS was determined with receiver operating characteristic (ROC) regression methodology [23] and used for the diagnosis of IR. CVRF and MetS were diagnosed based on the 2007 International Diabetes Federation (IDF) consensus statement on the clinical definition of the MetS in the pediatric age range. These criteria include central obesity plus 2 of the 4 following factors: abdominal obesity (WC $\geq 80$ and $90 \mathrm{~cm}$ in females and males, resp.), high blood pressure ( $\mathrm{SBP} \geq 130, \mathrm{DBP} \geq 85$ ), hypertriglyceridemia (TG $\geq 150 \mathrm{mg} / \mathrm{dL}$ ), low HDL ( $\leq 50$ and $\leq 40 \mathrm{mg} / \mathrm{dL}$ in female and male adolescents, resp.) and fasting hyperglycemia (Gli $\geq$ $100 \mathrm{mg} / \mathrm{dL}$ ) [24].

2.2.3. Diet and Physical Activity. Food intake and physical activity (PA) habits were evaluated using validated and standardized self-report questionnaires, scored from 0 to 10 , with higher scores denoting more nutritious food intake or more physical activity $[25,26]$. The questionnaires were administered by a researcher during the half-day assessment. The quality of food intake was measured by the amount of saturated fat, fiber, sugars, and salt in the food items. We applied cutoffs established by Burrows et al. [25] to classify the eating habits of participants into three groups: unhealthy (scores $\leq 25$ th percentile), intermediate (scores 26 th to 74 th percentile), and healthy (scores $\geq 75$ th percentile). PA was measured by the total amount of time devoted to sedentary activities, recreational games, active commuting, and weekly scheduled exercise either school or nonschool organized. Participants with scores $\leq 25$ th percentile were considered as physically inactive, those with scores $\geq 75$ th percentile were physically active, and those in between were moderately active. 
2.2.4. Family History of Type 2 Diabetes. A standardized questionnaire of FHDM, including first- and second-degree relatives, was answered by the participant's primary caregiver (father, mother, or grandparents). Reporting FHDM in at least one parent or grandparent was required to fit our definition of positive FHDM.

2.3. Statistical Analysis. Data were analyzed using Stata for Windows version 12.0 (Lakeway Drive College Station, TX, US). A $P$ value of $<0.05$ denoted statistical significance. Statistical analysis included chi-square tests for categorical variables and Student's $t$-test for comparison of mean values of anthropometric and cardiometabolic variables. ROC analysis was used to find the optimal cutoff of HOMAIR for diagnosis of IR. Bivariate analyses were used to test the association between obesity, sarcopenia, unhealthy food intake, physical inactivity, and FHDM and the outcome, IR. We used multiple logistic regressions to assess the influence of the variables significantly associated with IR. We excluded data on participants who reported unknown information in at least one parent or grandparent $(n=125)$. Four models were estimated. The first one included FHDM and low PA as independent variables. In the second model, obesity was added. The third model included sarcopenia. Finally, a full adjusted model contained all mentioned covariates with the addition of low adiponectin. The likelihood ratio test was performed to test the overall significance of all coefficients in the multiple adjusted models, whereas the Hosmer-Lemeshow goodness-of-fit test was used to evaluate their effectiveness in predicting the outcome of IR.

\section{Results and Discussion}

\subsection{Results}

3.1.1. Patients' Characteristics. Our sample was made up of $52.2 \%$ male and $47.8 \%$ female adolescents who were on average 16.8 (SD 0.3) years old. The prevalence of obesity was $16.2 \%$ whereas $9.4 \%$ of participants met criteria for MetS.

\subsubsection{Optimal Cutoff Point for the Diagnosis of Insulin Resis-} tance. A HOMA-IR value of 2.6 showed the best sensitivity (59\%) and specificity (87\%) for diagnosing MetS (AUC: 0.821; correctly classified: $87 \%$; LR+: 4.5) (Figure 1). According to this optimal cutoff point, $16.3 \%$ of adolescents in the sample had IR.

As shown in Table 1, adolescents with IR (HOMA-IR $\geq$ 2.6) had significantly higher $(P<0.001)$ BMI $z$ score, WC, fat mass (\%), systolic and diastolic BAP, total cholesterol, LDL-chol, triglyceride, glucose, and insulin, as well as significantly lower mean values of lean mass (\%), HDL-chol, and adiponectin compared to adolescents with HOMA-IR < 2.6. Obesity $(40.4 \%$ versus $9.3 \% ; P<0.001)$ and physical inactivity (51.4\% versus $37.4 ; P=0.006)$ were significantly higher among participants with IR compared to the insulin sensitive group. Similarly, adolescents with IR (Figure 2) show a significantly higher prevalence of abdominal obesity (61.5\% versus $27.8 \% ; P<0.001)$, high blood pressure $(18.4 \%$

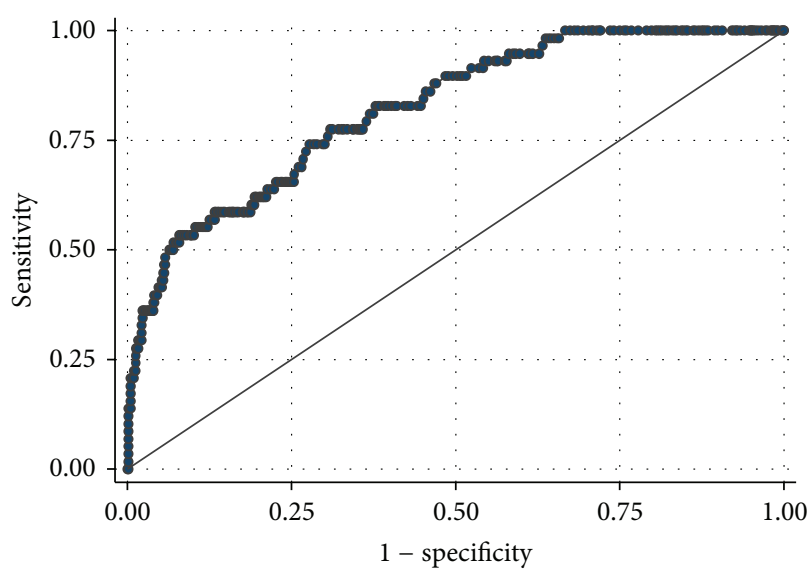

Area under curve: 0.821 ; correctly classified: $86 \%$; LR+: 4.5

FIGURE 1: ROC curve to determine the optimal cutoff value of HOMA-IR for MetS diagnosis in healthy adolescents.

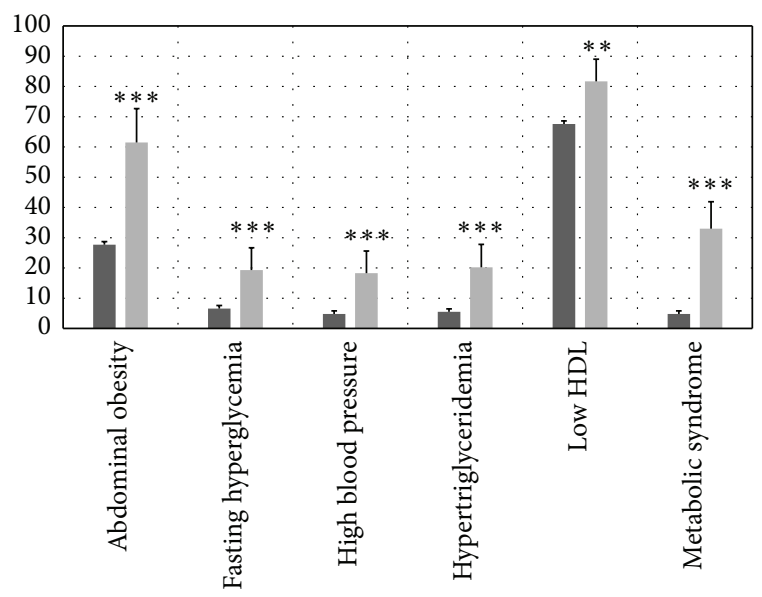

HOMA-IR $<2.6$

HOMA-IR $\geq 2.6$

Figure 2: Prevalence rates of cardiovascular and metabolic risk factors by HOMA-IR. Error bars are 95\% CI. Statistical significant difference by Pearson's Chi2. Significance level: ${ }^{*} P<0.05 ;{ }^{* *} P<$ $0.01 ;{ }^{* * *} P<0.001$.

versus $4.8 \% ; P<0.001)$, fasting hyperglycemia $(19.3 \%$ versus $6.6 \% ; P<0.001)$, hypertriglyceridemia $(20.4 \%$ versus $5.6 \%$; $P<0.001)$, and MetS (33.0\% versus $4.8 \% ; P<0.001)$.

3.1.3. Association of IR with Genetic, Biological, and Environmental Factors. Table 2 contains the results of the bivariate analysis that was used to identify explanatory variables of IR in adolescents. We found a significant association between IR and obesity (OR: 6.6; 95\% CI: 4.1-10.6), sarcopenia (OR: 4.9; 95\% CI: 3.2-7.5), low adiponectin (OR: 2.5; 95\% CI: 1.6-4.0), physical inactivity (OR: 1.8; 95\% CI: 1.2-2.7), and FHDM (OR: 1.7; 95\% CI: 1.1-2.9).

Table 3 shows the results of the multivariate logistic regression analyses assessing the relationship between genetic, biological, and environmental variables significantly 
TABLE 1: Background characteristics of adolescents in the sample by insulin sensitivity $(n=667)$.

\begin{tabular}{|c|c|c|c|c|}
\hline & $\begin{array}{c}\text { HOMA-IR }<2.6 \\
(n=558)\end{array}$ & $\begin{array}{c}\text { HOMA-IR } \geq 2.6 \\
\quad(n=109)\end{array}$ & Total sample & $P$ value $^{\mathrm{c}}$ \\
\hline Age (years) & $16.8 \pm 0.3^{\mathrm{a}}$ & $16.9 \pm 0.2$ & $16.8 \pm 0.3$ & n.s. \\
\hline \multicolumn{5}{|l|}{ Anthropometrics } \\
\hline BMI ( $z$ score $)$ & $0.48 \pm 1.1$ & $1.53 \pm 1.2$ & $0.65 \pm 1.2$ & $<0.001$ \\
\hline $\mathrm{WC}(\mathrm{cm})$ & $79.4 \pm 9.9$ & $90.4 \pm 14.3$ & $81.2 \pm 11.4$ & $<0.001$ \\
\hline Lean Mass (\%) & $68.7 \pm 11.4$ & $62.0 \pm 9.4$ & $67.6 \pm 11.1$ & $<0.001$ \\
\hline Fat mass (\%) & $27.9 \pm 10.7$ & $34.7 \pm 9.4$ & $29.0 \pm 10.8$ & $<0.001$ \\
\hline BMI $z \geq 2$ SD & $52(9.3)^{\mathrm{b}}$ & $44(40.4)$ & $96(14.4)$ & $<0.001^{\mathrm{d}}$ \\
\hline \multicolumn{5}{|l|}{ CVM profile } \\
\hline SBP (mm Hg) & $111.1 \pm 10.2$ & $118.3 \pm 10.7$ & $112.2 \pm 10.6$ & $<0.001$ \\
\hline DBP (mm Hg) & $68.7 \pm 7.0$ & $72.1 \pm 6.5$ & $69.3 \pm 7.0$ & $<0.001$ \\
\hline $\mathrm{TG}(\mathrm{mg} / \mathrm{dL})$ & $82.5 \pm 45.5$ & $118.2 \pm 71.6$ & $88.3 \pm 50.1$ & $<0.001$ \\
\hline HDL-chol (mg/dL) & $40.8 \pm 10.6$ & $36.6 \pm 10.2$ & $40.1 \pm 10.6$ & $<0.001$ \\
\hline Glucose (mg/dL) & $87.4 \pm 8.8$ & $94.2 \pm 10.8$ & $88.6 \pm 9.5$ & $<0.001$ \\
\hline Insulin $(\mu \mathrm{IU} / \mathrm{dL})$ & $6.3 \pm 2.5$ & $17.5 \pm 7.0$ & $8.1 \pm 5.5$ & $<0.001$ \\
\hline hs-CRP (mg/L) & $0.95 \pm 1.9$ & $1.10 \pm 1.6$ & $0.98 \pm 1.9$ & n.s. \\
\hline Adiponectin $(\mu \mathrm{g} / \mathrm{mL})$ & $12.3 \pm 5.5$ & $9.2 \pm 5.1$ & $11.8 \pm 5.5$ & $<0.001$ \\
\hline \multicolumn{5}{|l|}{ Lifestyles habits } \\
\hline Unhealthy eating & $139(24.9)$ & $20(18.4)$ & $159(23.8)$ & n.s. \\
\hline Physical inactivity & $209(37.4)$ & $56(51.4)$ & $265(39.7)$ & $0.006^{\mathrm{d}}$ \\
\hline
\end{tabular}

${ }^{\mathrm{a}}$ Mean \pm S.D; ${ }^{\mathrm{b}} n(\%) ;{ }^{\mathrm{c}}$ Student's $t$-test, except as indicated. ${ }^{\mathrm{d}}$ Chi2 (Pearson).

TABLE 2: Association between IR and sex, obesity, sarcopenia, low adiponectin, life-style habits, and HFDM2 in adolescents ( $n=667)$.

\begin{tabular}{|c|c|c|c|}
\hline & \multicolumn{2}{|c|}{ Subjects with insulin resistance (HOMA-IR $\geq 2.6$ ) } & \multirow{2}{*}{ Crude $\mathrm{OR}^{\mathrm{a}}$} \\
\hline & $n$ & $\%$ & \\
\hline Overall & 109 & 16.32 & \\
\hline \multicolumn{4}{|l|}{ Obesity } \\
\hline No & 65 & 11.4 & Ref. group \\
\hline Yes & 44 & 45.8 & $6.60[4.09-10.6]^{* * *}$ \\
\hline \multicolumn{4}{|c|}{ Sarcopenia } \\
\hline No & 50 & 10.8 & Ref. group \\
\hline Yes & 59 & 35.1 & $4.87[3.17-7.50]^{* * *}$ \\
\hline \multicolumn{4}{|c|}{ Low adiponectin } \\
\hline No & 74 & 13.6 & Ref. group \\
\hline Yes & 35 & 28.5 & $2.53[1.59-4.01]^{* * *}$ \\
\hline \multicolumn{4}{|c|}{ Physical inactivity } \\
\hline No & 53 & 13.2 & Ref. group \\
\hline Yes & 56 & 21.1 & $1.77[1.17-2.67]^{* * *}$ \\
\hline \multicolumn{4}{|c|}{ Unhealthy food intake } \\
\hline No & 89 & 17.5 & Ref. group \\
\hline Yes & 20 & 12.6 & $0.68[0.40-1.14]^{* * *}$ \\
\hline \multicolumn{4}{|c|}{ Family history $\mathrm{T} 2 \mathrm{D}^{\mathrm{b}}$} \\
\hline No & 23 & 11.7 & Ref. group \\
\hline Yes & 74 & 18.8 & $1.73[1.10-2.88]^{* * *}$ \\
\hline
\end{tabular}


TABLE 3: Influence of FHDM, physical inactivity, sarcopenia, obesity, and low adiponectin over the risk of insulin resistance $(n=590)$.

\begin{tabular}{lcccc}
\hline & Model 1 & Model 2 & Model 3 & Model 4 \\
& OR [95\% CI] & OR [95\% CI] & OR [95\% CI] & OR [95\% CI] \\
\hline FHDM & $1.74[1.10-2.88]^{*}$ & $1.74[1.10-2.94]^{*}$ & $1.72[1.10-2.92]^{*}$ & $1.80[1.10-3.08]^{*}$ \\
Physical inactivity & $1.77[1.14-2.75]^{*}$ & $1.49[0.94-2.37]$ & $1.42[0.89-2.26]$ & $1.45[0.90-2.34]$ \\
Sarcopenia & $(\cdots)$ & $4.25[2.67-6.75]^{* * *}$ & $2.27[1.25-4.12]^{* *}$ & $2.56[1.21-4.07]^{* *}$ \\
Obesity & $(\cdots)$ & $(\cdots)$ & $3.25[1.71-6.19]^{* * *}$ & $2.92[1.51-5.66]^{* *}$ \\
Low adiponectin & $(\cdots)$ & $(\cdots)$ & $(\cdots)$ & $2.22[1.30-3.77]^{* *}$ \\
\hline Likelihood ratio (Chi2) & $11.46^{* *}$ & $48.5^{* * *}$ & $61.6^{* * *}$ & $69.8^{* * *}$ \\
Hosmer-Lemeshow & $<0.001(0.99)$ & $0.39(0.99)$ & $0.18(0.99)$ & $1.21(0.98)$ \\
Correctly classified & $83.6 \%$ & $83.6 \%$ & $84.2 \%$ & $84.6 \%$ \\
\hline
\end{tabular}

OR [95\% CI]: odd ratio [95\% confidence interval]. Statistical significance: ${ }^{*} P<0.05 ;{ }^{* *} P<0.01$; ${ }^{* * *} P<0.001 .[\cdots]$ : nonobserved. OR [95\% CI]: odd ratio [95\% confidence interval]. FHDM: family history of type 2 diabetes in at least one first-degree relative. Obesity: BMI $z$ score $\geq 2$ SD; sarcopenia: FFMI $\leq 25$ th percentile; physical inactivity: PA score $\leq 3$; low adiponectin: adiponectin $\leq 7.9 \mu \mathrm{g} / \mathrm{mL}$.

associated in the bivariate analyses with the outcome, IR. Those with physical inactivity had significantly higher odds of IR in Model 1. However, the association was lost when sarcopenia, obesity, and low adiponectin were entered in the regression equation. In a fully adjusted model, FHDM (OR: 1.79; 95\% CI: 1.1-3.1), sarcopenia (OR: 1.9; 95\% CI: 1.1-3.6), obesity (OR: 2.4 ; 95\% CI: 1.2-4.9), and low adiponectin (OR: 2.3; 95\% CI: 1.3-3.8) significantly increased the risk of IR.

3.2. Discussion. In this cohort of healthy Chilean adolescents of low to middle SES, the optimal cutoff point of HOMAIR for IDF MetS diagnosis was 2.6 (sensitivity: 59\% and specificity: $87 \%$ ). Adolescents with HOMA-IR $\geq 2.6$ showed a significantly higher prevalence of obesity (40.4\%), abdominal obesity (61.5\%), hypertriglyceridemia (20.4\%), high blood pressure (18.4\%), fasting hyperglycemia (19.3\%), and MetS (33.0\%). Thus, HOMA-IR of 2.6 or higher would find young individuals with greater biological risk.

In adolescents, HOMA-IR values ranging from 2.2 to 5.3 have been reported as cutoff for diagnosing MetS, but these studies vary greatly in their design, sample size, age and nutritional status of participants, and degree of pubertal development [14, 15, 19, 20, 27-29]. Our findings are similar to population-based studies in a number of other contexts $[20,28]$. In Chinese children aged 6 to 18 years, 2.6 was the optimal cutoff point of HOMA-IR for MetS ATP III diagnosis [20]. In urban adolescents from India, aged 10 to 18 years, HOMA-IR value of 2.5 had the optimal sensitivity $(>70 \%)$ and specificity ( $>60 \%$ ) for MetS ATP III and IDF diagnosis [28]. This cutoff was most likely to detect MetS in adolescents from different BMI categories [28]. Other clinical studies also agree with our finding. In prepubertal overweight Brazilian children, HOMA-IR value of 2.5 showed optimal sensitivity (61\%) and specificity (74\%) for MetS diagnosis [30].

In this sample, FHDM, obesity, sarcopenia, and low adiponectin were all independently associated with a significant increased risk of IR. All these factors have been recognized as important determinants of IR and TD2 in pediatric populations $[3,4,31-37]$. In studies of twins, $50 \%$ of the variance in insulin sensitivity and secretion was attributed to genetic factors [31]. Furthermore, healthy children with
FHDM were more likely than those without to be insulin resistant, with an impaired balance between insulin sensitivity and secretion [32]. Moreover, obesity is the most prevalent pathophysiological determinant of IR, whereas insulin sensitivity is inversely associated with BMI and percent body fat in child and adolescent populations [33]. Similarly, muscular strength has been identified as an independent and powerful predictor of better insulin sensitivity and, conversely, lower muscular strength and higher central adiposity are highly predictive of higher levels of IR in healthy children and adolescent [34]. Moreover, there is growing evidence that exercise exerts beneficial effects partly through alterations in the adipokine profile; that is, exercise increases secretion of antiinflammatory adipokines, improves metabolic syndrome and insulin sensitivity, and reduces proinflammatory cytokines [35]. Finally, in children, adiponectin levels are lowered with MetS and obesity and inversely related to IR [36]. In both liver and skeletal muscle, adiponectin reduces triglyceride content and improves insulin signaling by increasing the gene expression involved in fatty acid oxidation and decreases the hepatic glucose production by inhibiting the expression of hepatic gluconeogenic enzymes [37]. Although IR has been shown to be linked with a chronic inflammatory state, we did not find significantly lower levels of hs_CRP in adolescents with HOMA-IR $<2.6$. However, it is important to emphasize that the observed levels of hs_CRP in this sample overall were higher than those reported by others using adolescent participants as well as the same measurement methodology $[38,39]$. Psychological factors related to stress, a diet high in saturated fat and refined sugars, and physical inactivity may be determinants of a systemic chronic inflammatory state [40-42]. These factors are usually more prevalent among low-SES groups $[43,44]$, and they all have been observed in this cohort. Whereas only 7.5\% (95\% CI: 5.5-9.5) of participants had healthy dietary habits, 19.3\% (95\% CI: 16.3-22.3) were considered to be physically active (data not shown), according to national references [16]. Similarly, results from a previous work suggest that adolescents, in our cohort, are exposed to a stressful environment [45].

This research has limitations that should be considered when interpreting its results. One limitation is that 
we estimated sarcopenia from DEXA scans and calculated fat-free mass rather than a more direct method of assessing muscle mass [46]. Nonetheless, this methodology has better sensitivity for estimating the ratio between muscle and fat tissue compared to BMI [22, 47]. Another limitation is that our sample is not representative of the Chilean adolescent population. Our sample is composed of adolescents from low to middle SES living in urban Santiago. However, our findings may be equally relevant for a number of reasons. According to the Chilean National Health Survey, the prevalence of obesity, TD2, and CVD is significantly higher among low to middle SES individuals [48]. On the other hand, low to middle SES Chilean adolescents are highly exposed to insulin resistance risk factors including obesity, physical inactivity, low fitness, and processed food full of fat and sugar [10, 12, $25,49-52]$. Our study also makes an important contribution in confirming that obesity, sarcopenia, and FHDM might be considered relevant risk factors for IR in adolescents.

\section{Conclusions}

This research provides results that confirm that in adolescents a value of HOMA-IR $\geq 2.6$ is associated with greater cardiovascular and metabolic risk $[20,28,30]$. We recommend this cutoff for diagnosis of IR in clinical practice. Adolescents with IR show a significantly higher prevalence of obesity, abdominal obesity, fasting hyperglycemia, and HFDM. In Chilean adult populations, fasting hyperglycemia, obesity, and self-reported FHDM were the best predictors of T2DM [53]. Obesity, sarcopenia, and FHDM might be considered relevant risk factors for insulin resistance. Our findings highlight the need for robust public policies and programs to reduce the risk for obesity and associated conditions in youth. For families with a history of diabetes mellitus, pediatricians should strongly counsel the youths and their parents to engage in healthy nutritional and physical activity practices in order to prevent the onset of early cardiometabolic risk.

\section{Conflict of Interests}

The authors declare that there is no conflict of interests regarding the publication of this paper.

\section{Acknowledgments}

This research was carried out with financial support from the National Heart Lung and Blood Institute (NHLBI) and National Institutes of Health (USA), under Grant R01HL088530-2980925. Dr. Correa-Burrows was sponsored by the Advanced Human Capital Program (Grant code: 79140003) and from the National Council for Scientific Research and Technology (CONICYT) (Chile).

\section{References}

[1] R. A. DeFronzo, "Insulin resistance, lipotoxicity, type 2 diabetes and atherosclerosis: the missing links. The Claude Bernard Lecture 2009," Diabetologia, vol. 53, no. 7, pp. 1270-1287, 2010.
[2] J. F. Ndisang, S. Rastogi, and A. Vannacci, "Insulin resistance, type 1 and type 2 diabetes, and related complications: current status and future perspective," Journal of Diabetes Research, vol. 2014, Article ID 276475, p. 2, 2014.

[3] F. Chiarelli and M. L. Marcovecchio, "Insulin resistance and obesity in childhood," European Journal of Endocrinology, vol. 159, no. 1, pp. S67-S74, 2008.

[4] C. Levy-Marchal, S. Arslanian, W. Cutfield et al., "Insulin resistance in children: consensus, perspective, and future directions," Journal of Clinical Endocrinology and Metabolism, vol. 95, no. 12, pp. 5189-5198, 2010.

[5] G. Q. Shaibi and M. I. Goran, "Examining metabolic syndrome definitions in overweight Hispanic youth: a focus on Insulin resistance," The Journal of Pediatrics, vol. 152, no. 2, pp. 171-176, 2008.

[6] M. Reyes, S. Gahagan, E. Díaz et al., "Relationship of adiposity and insulin resistance mediated by inflammation in a group of overweight and obese Chilean adolescents," Nutrition Journal, vol. 10, no. 4, pp. 4-7, 2011.

[7] L. Huicho, M. Trelles, F. Gonzales, W. Mendoza, and J. Miranda, "Mortality profiles in a country facing epidemiological transition: an analysis of registered data," BMC Public Health, vol. 9, article 47, 2009.

[8] C. Compher, "The nutrition transition in American Indians," Journal of Transcultural Nursing, vol. 17, no. 3, pp. 217-223, 2006.

[9] P. López-Jaramillo, S. Y. Silva, N. Rodríguez-Salamanca, A. Duràn, W. Mosquera, and V. Castillo, "Are nutrition-induced epigenetic changes the link between socioeconomic pathology and cardiovascular diseases?" The American Journal of Therapeutics, vol. 15, no. 4, pp. 362-372, 2008.

[10] C. Albala, F. Vio, J. Kain, and R. Uauy, "Nutrition transition in Chile: determinants and consequences," Public Health Nutrition, vol. 5, no. 1, pp. 123-128, 2002.

[11] F. Vio, C. Albala, and J. Kain, "Nutrition transition in Chile revisited: mid-term evaluation of obesity goals for the period 2000-2010," Public Health Nutrition, vol. 11, no. 4, pp. 405-412, 2008.

[12] J. Kain, R. Uauy, L. Lera, M. Taibo, and C. Albala, “Trends in height and BMI of 6-year-old children during the nutrition transition in Chile," Obesity Research, vol. 13, no. 12, pp. 21782186, 2005.

[13] S. Muzzo, R. Burrows, J. Cordero, and I. Ramírez, “Trends in nutritional status and stature among school-age children in Chile," Nutrition, vol. 20, no. 10, pp. 867-872, 2004.

[14] R. Burrows, G. Weisstaub, Z. Ceballos et al., "Metabolic syndrome in children and adolescents: association with insulin sensitivity, degree and distribution of overweight," Revista Médica de Chile, vol. 135, no. 2, pp. 174-181, 2007.

[15] R. A. Burrows, L. B. Leiva, G. Weisstaub et al., "High HOMAIR, adjusted for puberty, relates to the metabolic syndrome in overweight and obese Chilean youths," Pediatric Diabetes, vol. 12, no. 3, pp. 212-218, 2011.

[16] T. M. Wallace and D. R. Matthews, "The assessment of insulin resistance in man," Diabetic Medicine, vol. 19, no. 7, pp. 527-534, 2002.

[17] R. Muniyappa, S. Lee, H. Chen, and M. J. Quon, "Current approaches for assessing insulin sensitivity and resistance in vivo: advantages, limitations, and appropriate usage," American Journal of Physiology_Endocrinology and Metabolism, vol. 294, no. 1, pp. E15-E26, 2008. 
[18] M. Keskin, S. Kurtoglu, M. Kendirci, M. E. Atabek, and C. Yazici, "Homeostasis model assessment is more reliable than the fasting glucose/insulin ratio and quantitative insulin sensitivity check index for assessing insulin resistance among obese children and adolescents," Pediatrics, vol. 115, no. 4, pp. e500e503, 2005.

[19] A. Esteghamati, H. Ashraf, O. Khalilzadeh et al., "Optimal cut-off of homeostasis model assessment of insulin resistance (HOMA-IR) for the diagnosis of metabolic syndrome: third national surveillance of risk factors of non-communicable diseases in Iran (SuRFNCD-2007)," Nutrition and Metabolism, vol. 7, article 26, 2010.

[20] J. Yin, M. Li, L. Xu et al., "Insulin resistance determined by Homeostasis Model Assessment (HOMA) and associations with metabolic syndrome among Chinese children and teenagers," Diabetology and Metabolic Syndrome, vol. 5, no. 1, article 71, 2013.

[21] B. Lozoff, I. de Andraca, M. Castillo, J. B. Smith, T. Walter, and P. Pino, "Behavioral and developmental effects of preventing irondeficiency anemia in healthy full-term infants," Pediatrics, vol. 112, no. 4, pp. 846-854, 2003.

[22] J. C. K. Wells and M. S. Fewtrell, "Measuring body composition," Archives of Disease in Childhood, vol. 91, no. 7, pp. 612-617, 2006.

[23] D. Faraggi, "Adjusting receiver operating characteristic curves and related indices for covariates," Journal of the Royal Statistical Society, Series D: The Statistician, vol. 52, no. 2, pp. 179-192, 2003.

[24] P. Zimmet, G. K. M. M. Alberti, F. Kaufman et al., "The metabolic syndrome in children and adolescents-an IDF consensus report," Pediatric Diabetes, vol. 8, no. 5, pp. 299-306, 2007.

[25] R. Burrows, E. Díaz, V. Sciaraffia et al., "Intake and physical activity habits among elementary and high school children according to type of school," Revista Médica de Chile, vol. 136, no. 1, pp. 53-63, 2008.

[26] M. C. Godard, M. P. Rodríguez, N. Díaz, M. L. Lera, R. G. Salazar, and A. R. Burrows, "Value of a clinical test for assessing physical activity in children," Revista Médica de Chile, vol. 136, no. 9, pp. 1155-1162, 2008.

[27] K. H. Yi, J. S. Hwang, E. Y. Kim, S. H. Lee, D. H. Kim, and J. S. Lim, "Prevalence of insulin resistance and cardiometabolic risk in Korean children and adolescents: a population-based study," Diabetes Research and Clinical Practice, vol. 103, no. 1, pp. 106113, 2014.

[28] Y. Singh, M. K. Garg, N. Tandon, and R. K. Marwaha, "A Study of insulin resistance by HOMA-IR and its cut-off value to identify metabolic syndrome in urban Indian adolescents," JCRPE Journal of Clinical Research in Pediatric Endocrinology, vol. 5, no. 4, pp. 245-251, 2013.

[29] S. Kurtoglu, N. Hatipoglu, M. Mazcoglu, M. Kendirci, M. Keskin, and M. Kondolot, "Insulin resistance in obese children and adolescents: HOMA-IR cut-off levels in the prepubertal and pubertal periods," Journal of Clinical Research in Pediatric Endocrinology, vol. 2, no. 3, pp. 100-106, 2010.

[30] I. Rey Madeira, C. N. Miranda Carvalho, F. Mussi Gazolla et al., "Ponto de corte do Índice Homeostatic Model Assessment for Insul in Resistance (HOMA-IR) avaliado pela curva receiver operating characteristic (ROC) na deteç̧ão de Síndrome Metabólica em crianças pré-púberes com excesso de peso," Arquivos Brasileiros de Endocrinologia \& Metabologia, vol. 52, no. 9, pp. 1466-1473, 2008.
[31] P. Poulsen, K. Levin, I. Petersen, K. Christensen, H. BeckNielsen, and A. Vaag, "Heritability of insulin secretion, peripheral and hepatic insulin action, and intracellular glucose partitioning in young and old Danish twins," Diabetes, vol. 54, no. 1, pp. 275-283, 2005.

[32] S. A. Arslanian, F. Bacha, R. Saad, and N. Gungor, "Family history of type 2 diabetes is associated with decreased insulin sensitivity and an impaired balance between insulin sensitivity and insulin secretion in white youth," Diabetes Care, vol. 28, no. 1, pp. 115-119, 2005.

[33] F. Bacha, R. Saad, N. Gungor, and S. A. Arslanian, "Are obesityrelated metabolic risk factors modulated by the degree of insulin resistance in adolescents?" Diabetes Care, vol. 29, no. 7, pp. 15991604, 2006.

[34] A. C. Benson, M. E. Torode, and M. A. F. Singh, "Muscular strength and cardiorespiratory fitness is associated with higher insulin sensitivity in children and adolescents," International Journal of Pediatric Obesity, vol. 1, no. 4, pp. 222-231, 2006.

[35] S. Golbidi and I. Laher, "Exercise induced adipokine changes and the metabolic syndrome," Journal of Diabetes Research, vol. 2014, Article ID 726861, 16 pages, 2014.

[36] S. N. Magge, N. Stettler, D. Koren et al., "Adiponectin is associated with favorable lipoprotein profile, independent of BMI and insulin resistance, in adolescents," Journal of Clinical Endocrinology and Metabolism, vol. 96, no. 5, pp. 1549-1554, 2011.

[37] S. Lee and H. Kwak, "Role of adiponectin in metabolic and cardiovascular disease," Journal of Exercise Rehabilitation, vol. 10, no. 2, pp. 54-59, 2014.

[38] E. S. Ford, U. A. Ajani, and A. H. Mokdad, "The metabolic syndrome and concentrations of C-reactive protein among US youth," Diabetes Care, vol. 28, no. 4, pp. 878-881, 2005.

[39] M. Lambert, E. E. Delvin, G. Paradis, J. O’Loughlin, J. A. Hanley, and E. Levy, "C-reactive protein and features of the metabolic syndrome in a population-based sample of children and adolescents," Clinical Chemistry, vol. 50, no. 10, pp. 17621768, 2004.

[40] P. H. Black and L. D. Garbutt, "Stress, inflammation and cardiovascular disease," Journal of Psychosomatic Research, vol. 52, no. 1, pp. 1-23, 2002.

[41] F. Jameel, M. Phang, G. Wood et al., "Acute effects of feeding fructose, glucose and sucrose on blood lipid levels and systemic inflammation," Lipids in Health and Disease, vol. 13, no. 1, article 195, 2014

[42] M. A. Nimmo, M. Leggate, J. L. Viana, and J. A. King, "The effect of physical activity on mediators of inflammation," Diabetes, Obesity and Metabolism, vol. 15, no. 3, pp. 51-60, 2013.

[43] B. H. Brummett, M. A. Babyak, A. Singh et al., "Socioeconomic indices as independent correlates of C-reactive protein in the national longitudinal study of adolescent health," Psychosomatic Medicine, vol. 75, no. 9, pp. 882-893, 2013.

[44] A. Nazmi, I. O. Oliveira, B. L. Horta, D. P. Gigante, and C. G. Victora, "Lifecourse socioeconomic trajectories and C-reactive protein levels in young adults: findings from a Brazilian birth cohort," Social Science and Medicine, vol. 70, no. 8, pp. 12291236, 2010.

[45] S. M. Martinez, E. Blanco, J. Delva et al., "Perception of neighborhood crime and drugs increases cardiometabolic risk in Chilean adolescents," Journal of Adolescent Health, vol. 54, no. 6, pp. 718-723, 2014. 
[46] S. Lee and J. L. Kuk, "Changes in fat and skeletal muscle with exercise training in obese adolescents: comparison of wholebody MRI and dual energy X-ray absorptiometry," Obesity, vol. 21, no. 10, pp. 2063-2071, 2013.

[47] T. L. Kelly, K. E. Wilson, and S. B. Heymsfield, "Dual energy $\mathrm{X}$-ray absorptiometry body composition reference values from NHANES," PLoS ONE, vol. 4, no. 9, Article ID e7038, 2009.

[48] Ministry of Health, National Health Survey 2009-2010, Ministry of Health, Santiago, Chile, 2011.

[49] Ministry of Education, Informe de Resultados Nacionales de Educación Física 2010, Ministry of Education, Santiago, Chile, 2010.

[50] F. Mardones, P. Arnaiz, S. Barja et al., "Nutritional status, metabolic syndrome and insulin resistance in children from Santiago (Chile)," Nutricion Hospitalaria, vol. 28, no. 6, pp. 1999-2005, 2013.

[51] V. Shrewsbury and J. Wardle, "Socioeconomic status and adiposity in childhood: a systematic review of cross-sectional studies 1990-2005," Obesity, vol. 16, no. 2, pp. 275-284, 2008.

[52] E. Agardh, P. Allebeck, J. Hallqvist, T. Moradi, and A. Sidorchuk, "Type 2 diabetes incidence and socio-economic position: a systematic review and meta-analysis," International Journal of Epidemiology, vol. 40, no. 3, pp. 804-818, 2011.

[53] E. Leiva, V. Mujica, R. Orrego et al., "Subjects with impaired fasting glucose: evolution in a period of 6 years," Journal of Diabetes Research, vol. 2014, Article ID 710370, 5 pages, 2014. 


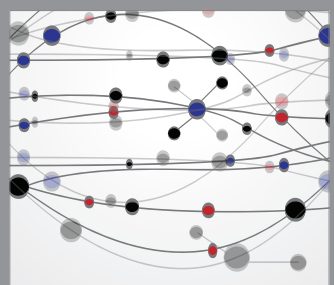

The Scientific World Journal
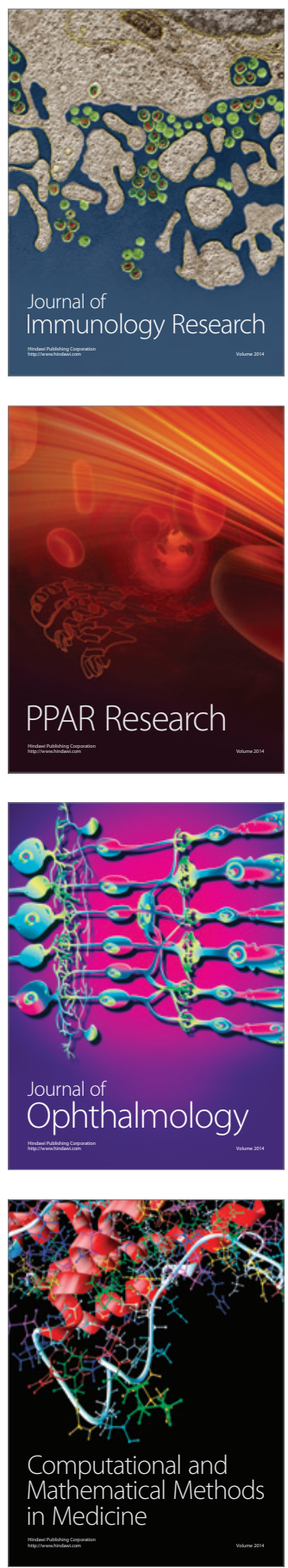

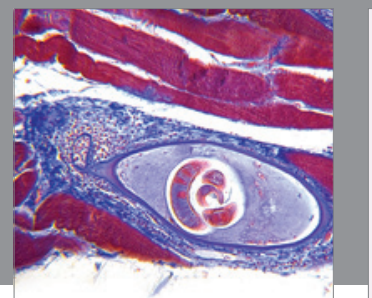

Gastroenterology

Research and Practice
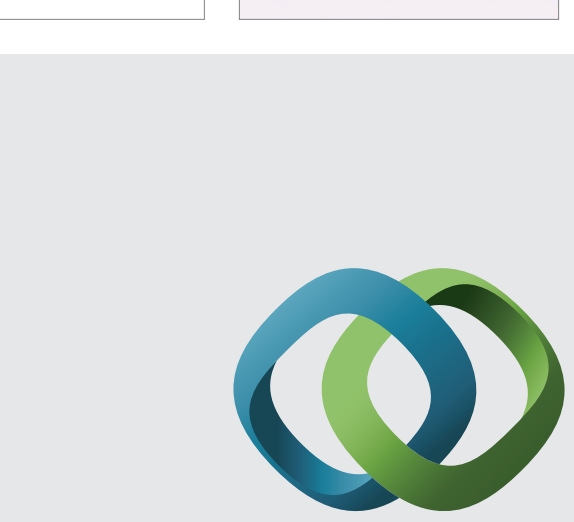

\section{Hindawi}

Submit your manuscripts at

http://www.hindawi.com
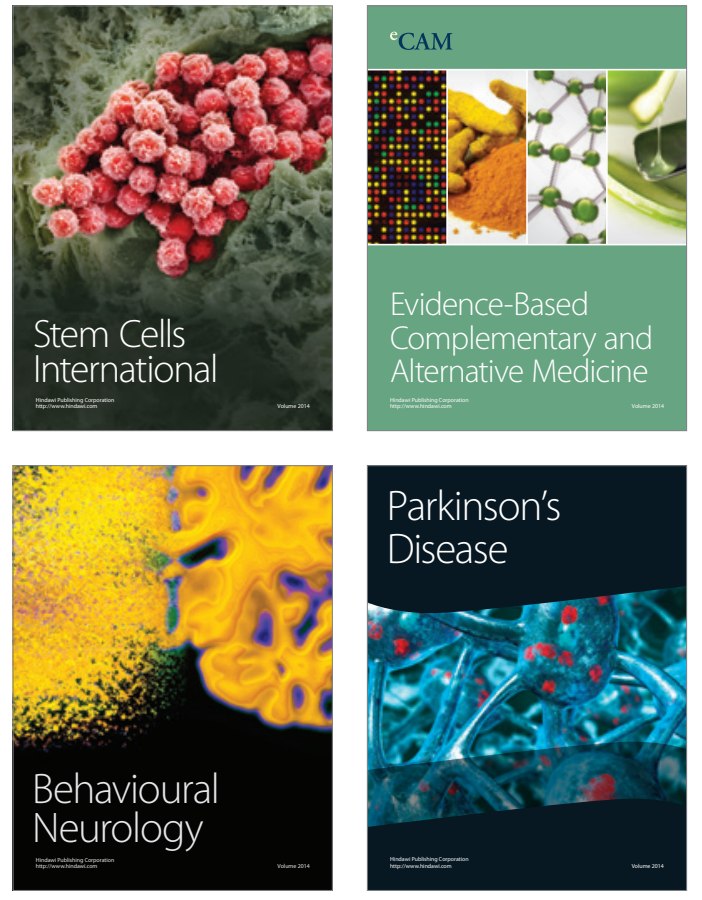
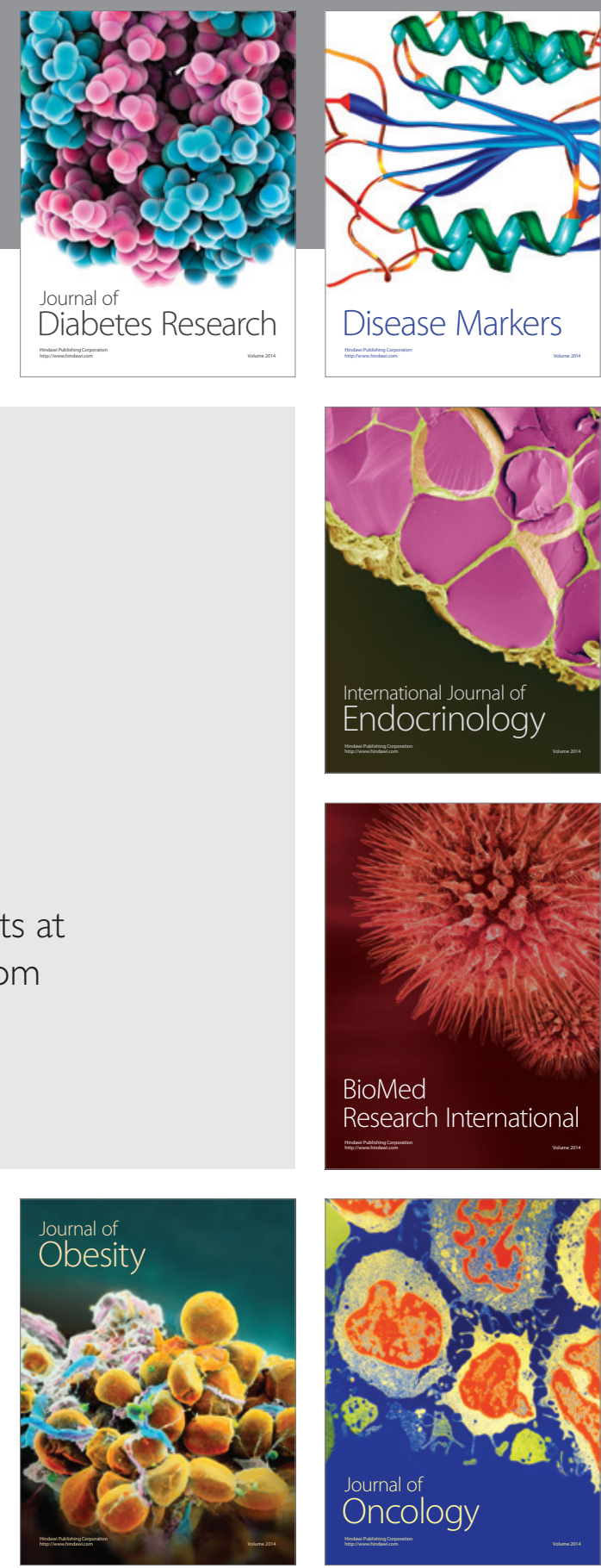

Disease Markers
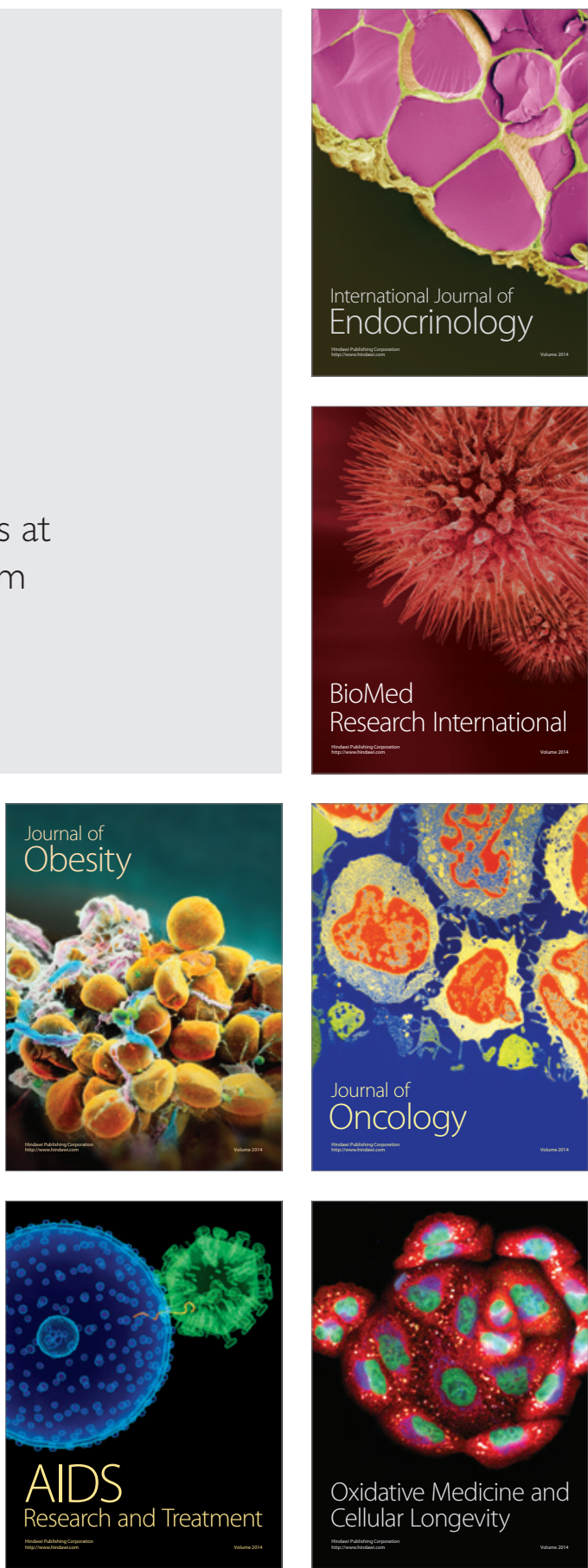